Cilt/Volume:14 Sayı/Issue:1 Ocak/January 2022

\title{
Aramid Elyaf Takviyeli Polimer Matris Kompozitlerin Mekanik Deney Sonuçlarının Yapay Sinir Ağlarıyla Tahminleri ve İstatistiksel Analizleri
}

\section{Predictions and Statistical Analysis of Mechanical Experiment Results of Aramid Fiber Reinforced Polymer Matrix Composites with Artificial Neural Networks}

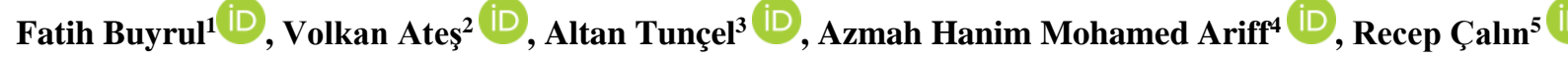 \\ ${ }^{1}$ Kırıkkale Üniversitesi, Savunma Teknolojileri Bölümü, 71450, Kırıkkale, TÜRKİYE \\ ${ }^{2}$ Kırıkkale Üniversitesi, Elektrik-Elektronik Mühendisliği Bölümü, 71450, Kırıkkale, TÜRKIYYE \\ ${ }^{3}$ Kırıkkale Üniversitesi, Aktüerya Bilimleri Bölümü, 71450, Kırıkkale, TÜRKİYE \\ ${ }^{4}$ Putra Üniversitesi, Makine ve İmalat Mühendisliği Bölümü, MALEZYA \\ ${ }^{5}$ Kırıkkale Üniversitesi, Metalurji ve Malzeme Mühendisliği Bölümü, 71450, Kırıkkale, TÜRKIYE
}

Başvuru/Received: 29/12/2021 Kabul/Accepted: 31/12/2021 Çevrimiçi Basım/Published Online: 31/01/2022

Son Versiyon/Final Version: 31/01/2022

\section{$\ddot{O} \mathbf{z}$}

Kompozit malzemelerde polimer matris en çok tercih edilen malzeme türlerinden biri haline gelmesi personel koruma ya da diğer zırh malzemesi türlerinde de kullanımını artmakla birlikte gelişmeye devam etmektedir. Mekanik deney sonuçlarını birçok yöntemle matematiksel modellemesi yapılırken en fazla tercih edilenlerden bir tanesi de yapay sinir ağları olmaktadır. Kompozit malzemelerin birden fazla parçacık ya da malzemelerin birleşimiyle oluşmasından dolayı birleşime dahil olan parça ya da malzemenin mekanik sonuçlara etkisinin anlamlı veya anlamsız olduğunu söylemenin en güzel yollarından biri de istatistiksel analizlerdir. İstatistiksel analizlerle bilgi ve yorumlanmasıyla birlikte diğer oran ya da türevlerinin kıyaslama ya da karşılama yapılmasına da olanak sağlamaktadır. Bu çalışmada; Numuneler 8 katlı Aramid elyaf takviyeli ve dolgu malzemesi olarak ağırlıkça $\% 0, \% 1, \% 2$ ve $\% 4$ oranında $\mathrm{TiB}_{2}$ ilaveli olup ayrıca $45^{\circ}$ ve $90^{\circ}$ oryantasyona sahip olarak üretilmiştir. Yapay sinir ağları ve İstatistiksel analizler ağırlıkça $\% 1 \mathrm{TiB}_{2}$ ilaveli ve $90^{\circ}$ oryantasyona sahip kompozitler diğer oranlara göre balistik amaca en anlamlı sonucu vermiştir.

\section{Anahtar Kelimeler}

"İ̧ İ̧̧e Tasarımlı ve Faktöriyel Varyans Analizi, Polimer Matrisli Kompozitler, Yapay Sinir Ağları, nftool, Kevlar-49, Aramid Elyaf”"

\begin{abstract}
In composite materials, the polymer matrix continues to develop as one of the most preferred material types, and its use in personnel protection or other armor material types is increasing. While mathematical modeling of mechanical test results with many methods is done, artificial neural networks are one of the most preferred ones. Statistical analysis is one of the best ways to say that the effect of the part or material included in the combination on the mechanical results is significant or insignificant, since composite materials are formed by more than one particle or combination of materials. It also allows comparison or compensation of other ratios or derivatives, along with information and interpretation through statistical analysis. In this study; The samples were produced with 8layer Aramid fiber reinforced and 0\%,1\%,2\% and 4\% TiB2 additions as filling material and also with $45^{\circ}$ and $90^{\circ}$ orientations. Artificial neural networks and Statistical analysis, composites with $1 \% \mathrm{TiB}_{2}$ addition and $90^{\circ}$ orientation gave the most significant result for ballistic purpose compared to other ratios.
\end{abstract}

Key Words

"Nested Design and Factorial Analysis of Variance, Polymer Matrix Composites, Artificial Neural Networks, nftool, Kevlar-49" 


\section{Giriş}

Personel koruma zırh teknolojileri için üretilen polimer matrisli kompozitlerin mekanik deneylerinin güvenirliğini sayısal ifadelerle tanımlamak ve ölçmek için analiz edilmesi gerekmektedir (Kubat C. vd. 2017). Elde edilen verilen önemini arz edebilmek farklı yöntemler mümkün olmakla birlikte yapay sinir ağlarıyla modellenip tahminlerinin karşılaştırılması ayrıca önem arz etmektedir. İstatistiksel yaklaşımlarla birlikte elde edilen malzemenin analizler için de en uygun deney tasarımının oluşturulması analizlerin daha iyi açıklanmasını sağlamaktadır (Akşehirli Ö. vd. 2012). Birçok etken ve faktörün birbirleriyle olan etkileşimini ve minimum hata ile açıklanması için kullanılan analizlerinden ikisi faktöriyel varyans analizi ya da iç içe tasarımlı varyans analizleridir (Eyecioğlu Ö. 2021; Gedik İ. 2010; Suresh N., 2021).

$\mathrm{Bu}$ analizler sayesinde verilerin merkezi eğilim ölçümleri hakkında bilgi verilmesi ya da yorumlanmasına olanak sağlamaktadır. Bu bilgiler ışı̆̆ında mod, medyan, ortalaması, standart sapması veya varyans gibi betimsel istatistiklerin açıklanmasının yanında birden çok faktörün birleriyle etkileşimlerin anlamlı ya da anlamsız olduğunu söyleyebilmeye olanak sağlamaktadır (Eyecioğlu Ö., 2021; Gedik İ., 2010). Bayesian Model Averaging çoklu verilere odaklı bir yöntemin entegrasyonu yoluyla toplu veriler üzerine bir model oluşturulur. Bu modelle; tek veya birçok parametre modeline dayalı istatistiksel çıkarımlar yoluyla bir dizi modelleme sonrası analiz yoluyla incelenmektedir (Wanga F. et al, 2021). Varyans analizi karar vermek ya da amaca uygunluğunu saptamak için aynı anda birkaç tür etkiye bağlı olan parametreleri analizini sağlayan istatistiksel yöntemlerden biridir (Kuwada M., 1993). Faktöriyel yapı, deneysel tasarımlarda genellikle tahmin parametreleri açısından değerlendirilir (Mays D.P. and Myers R.H., 1997). Birden fazla faktörlerin olması istatistiksel analizleri daha karmaşık bir hale gelmesine sebep olabilir. Böyle durumlarda, analizdeki her bir faktörün deneylerdeki bir faktörü temsilen oluşturduğu çok faktörlü bir varyans analiziyle (ANOVA) analizleri yapılabilmektedir. Bu analizler sayesinde iki veya daha fazla parametrenin ortalamaları arasında istatistiksel olarak anlamlı ya da anlamlı bir fark olup olmadığına karar vermemize olanak sağlayan bir F hesap değeri oluşturmaktadır (Morrison D.A., 2002). Dört karma ve iki grup modelden analizlerden P -değerleri sayesinde parametreler hakkında istatistiksel bilgiler vermektedir. Bu bilgiler ışığında yorumlanması mümkün olmuştur (Stanimirova L., 2013).

Kevlar 49 aramid elyafının $350^{\circ}-550^{\circ} \mathrm{C}$ sıcaklık aralı̆̆ında kadar termal bozunma korunmakta olup vakumda $470^{\circ} \mathrm{C}$ 'nin üzerinde ve havada ise $370^{\circ} \mathrm{C}$ 'nin üzerinde bozunma gerçekleşmektedir (James R. et al, 1982). Çok güçlü polimer matrisli malzemeler üretimi için aramid elyaf takviyesi en çok tercih edilenlerden olmaktadır (Balaji R. et al, 2019). Kevlar 49 takviye malzemesi olarak en çok kullanılan polimer matrisli kompozit malzemelerdendir. Bu özelliğinin en belirgin birkaç özelliği yüksek mukavemet ve korozyon oldukça dirençli olmasıdır. Böylece savunma teknolojilerinde havacılık ve uzay endüstrilerinde yaygın olarak kullanılmaktadır (Madara S.R., 2021). Yaklaşan endüstriyel ihtiyaçlar doğrultusunda polimer matrisli malzemeler yüksek performans sergilemesi daha çok tercih edilmesine ve yapay sinir ağlarıyla öğrenme ve modellemeler sayesinde zaman kazandırması ve gelecekteki mekanik etkilerini belirmeye yardımcı olmaktadır (Kumar S. et al, 2021). Polimer matrisli malzemelerin sertliğini, sıkıştırmayı ve ısıl iletkenliği artıran dolgu maddeleri de büyük avantaj sağlamaktadır. Üretim aşamasında kazanılan pratikler, örneğin; kürleme sıcaklıkları ile üretim hızındaki değişimleri belirlemesiyle polimer matrisli kompozitlerin kalitesini belirlemektedir. Farklılıkları yorumlamak ve göstermek için analiz yaparak optimal durumları belirlenmektedir (Zhang Z. and Friedrich K. 2003). Yapay sinir ağlarının kullanımı her geçen artmakta ve polimer kompozitlerin özelliklerini analiz edip optimize etmektedir (Nguyen H.T. vd. 2021). Elde edilen veriler sayesinde yapay sinir ağları tahminleriyle doğruluğunu gösterilmektedir (Ramaiah G.B. et al, 2021). Yapay sinir ağları uluslararası araştırmalarda en çok yaygınlaşan bir araştırma yöntemi haline gelmesi öngörü ve araştırmaların daha nitelikli hale gelmesiyle herkes tarafından benimsenmektedir. Tüm bunların yanında karmaşıklık, hız, sıcaklık, mekanik özelliklerin davranışı ve akma dayanımı gibi davranışlar polimer matris kompozitlerin parametreleri hakkında bilgi vermektedir. Bu parametreler de daha doğru şekilde gelecekteki tepkileri tahmin edebilme ve modellemeyi mümkün kılmaktadır (Fazilat H.et al, 2012). Çok değişkenli doğrusal olmayan modeller olup analitik olarak test verilerinden yararlanarak tanıma ve tahmin etmeye yönelik doğrudan bir yapay sinir ağ oluşturmakla birlikte tahmin verilerini oluşturmaktadır (Balaji N.S. et al, 2016). Tahminlerde bulunmak için regresyon modelindeki kayıp ortalamayı (ortalama hataların karesi) MSE olarak hesaplanmakla olup gerçek verilerden uzak olmaktadır. Bu uzaklık oranlarının doğruluğunu gerçek verilerin yüzdesi olarak gören yani ortalama hataları MAPE olarak hesaplanmaktadır (Chen CT et al, 2019; Saraç M.F. vd., 2018). İncelenen birçok uygulama ve çalışmalarda da ileri beslemeli, geriye yayılımlı olan algoritmaların kullanıldığı görülmektedir (Kadi H.E., 2006; Okkan U. et al, 2018). Yapay sinir ağlarıyla tahminleri yapılırken Mean Squared Error (MSE) olarak ortalama hataların karesini ve Mean Absolute Error (MAPE) olarak ortalama mutlak hataları gösterilmesinde kullanılan yöntemlerdendir (Chen CT et al, 2019; Saraç M.F. vd., 2018). MSE (a) ve MAPE (b) formülleriyle hesaplanmaktadır (Chen CT et al, 2019).

$$
\text { (a) MSE }=\frac{\sum_{i=1}^{n}\left(y_{i}-\hat{y}_{i}\right)^{2}}{n}=\frac{\sum_{i=1}^{n}(\text { tahmini hatalar })^{2}}{n} \quad \text { (b) MAPE }=100 \cdot \frac{\sum_{i=1}^{n} \frac{\mid g_{\text {ercek }}-\text { tahmin }_{i} \mid}{\operatorname{gercsek}_{i}}}{n}
$$

Bu çalışmada, mekanik test sonuçlarından elde edilen verilerden yararlanarak matlab programında bulunan Lavenberg-Marquardt sonra Bayesian Regularization ve daha sonra da Scaled Conjugate Gradient algoritmaları kullanılarak yapay sinir ağlarıyla tahminleri yapılmıştır. Betimsel istatistiklerle sunulmasının yanında faktöriyel varyans analizi ile iç içe tasarımlı varyans analizleri yapılmıştır. $\mathrm{Bu}$ analizlerle polimer kompozit malzemesinin üretim parametreleri hakkında bilgi edinme, yorum yapabilme ve parametrelerin tek başına ya da diğerleriyle birlikte etkisinin anlamlı olup olmadığını yorumlayabilmek için istatistiksel analizler yapılmıştır. 


\section{Materyal ve Metot}

\subsection{Yapay Sinir Ağları Çalışmaları}

Matlab programında nftool (Neural Fitting Tool) yöntemiyle yapay sinir ağlarında standart olarak ikili problemler kullanılmaktadır. Yapay sinir ağlarında eğri uydurmakta çok iyi olduğu bilinmektedir. Elde edilmiş ya alınmış verilerin tanımlanarak girdi ve çıtı verilerini matlab programına aktararak analizleri yapılabilmektedir. İçerisinde bulundurduğu algoritmalardan ilki LavenbergMarquardt sonra Bayesian Regularization ve diğeri ise Scaled Conjugate Gradient algoritmalarıdır. Bu algoritmaları denedikten sonra optimal olanı tercih edilerek kullanılmaktadır. Bu algoritmaların her biri geriye doğru yayılım göstermektedir. Bu modellerin bir ortak yanı da değişkenlerin gizli katman sayısıyla, çok katmanlılık ve tek yönlü bir algoritmalar halinde olmasıdır. Denemelerle tekrar edilerek deneme-yanılma yöntemiyle analizler yapılmakta olup en iyi sonucu elde edilene kadar eğitimler devamlı olarak yapılabilmektedir (Kubat C. vd., 2017).

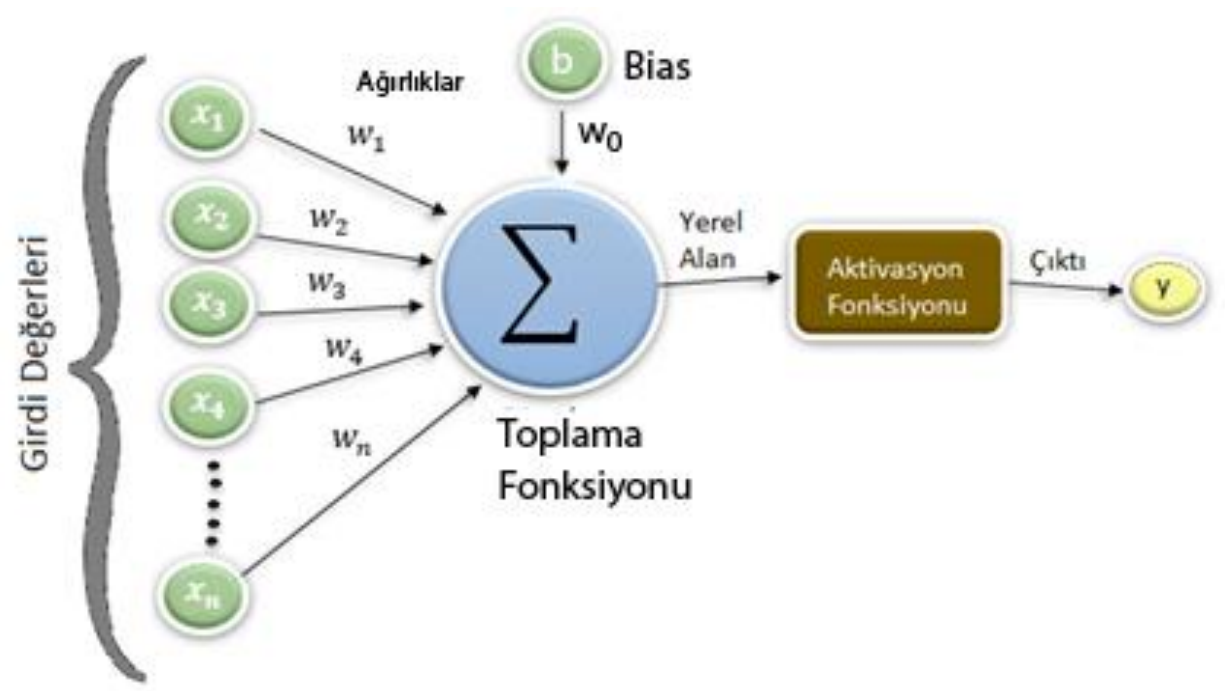

Şekil 1. Yapay Sinir Ağlarının Nöron Yapısı (Kubat C. vd., 2017).

\section{2. İstatistiksel Çalışmalar}

Betimsel İstatistik, deneysel olarak oluşturulan verilerin ya da verilerin genel özelliklerini tanımlayan bilgi veya veri ölçümlerinin sayısal olarak gösterilmesine ya da sunulmasına olanak sağlamaktadır. İç İçe Tasarımlı Varyans Analizi, Her bir seviyenin kendi alt alta birimlerden oluşan kısımlarına etken ve faktörlerin incelenmesine imkân sağlamaktadır. Faktöriyel Varyans Analizi, İki ya da daha fazla faktörün sonuçların ana etkisini aynı anda incelemekle birlikte birden fazla etkenin aynı anda etkisini ölçmeye ya da yorumlamaya olanak sağlamaktadır (Eyecioğlu Ö., 2021; Gedik İ., 2010). Kompozit malzemelerin mekanik testlerinin yanında mutlaka istatistiksel analizlerinin de yapılması gerekmektedir. Bunun en bilindik nedenlerinden bazıları malzemenin homojenliği ve anizotropik davranışlarına sahip olmasından kaynaklanmaktadır. Varyans analizleri sayesinde deneysel sonuçların her bir parametre için parametreler arasında önemli farklılıklar ayırt edebilme ve en anlamlı parametreyi belirlemek daha doğru bir sonuca gidebilmeyi sağlamaktadır (Suresh N. 2021).

\section{Bulgular ve Tartışma}

Yapay sinir ağları ile tahminleri yapılmıştır. Birçok parametrenin plakalara ayrı ayrı ya da birlikte etkisini değerlendirmek ve parametrelerin anlamlılığını yorumlayabilmek için ise istatistiksel analizler yapılmıştır. 


\subsection{Yapay Sinir Ă̆ Sonuçları}

a)

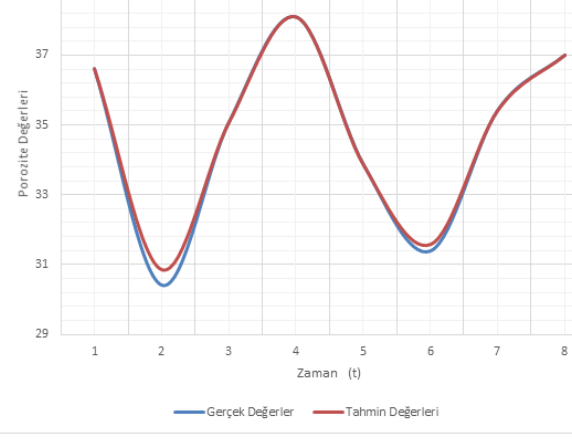

b)
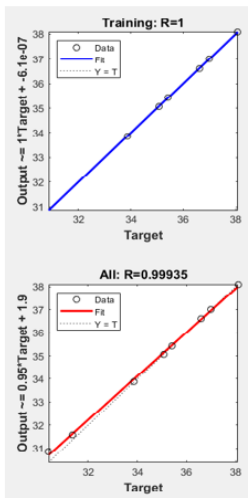

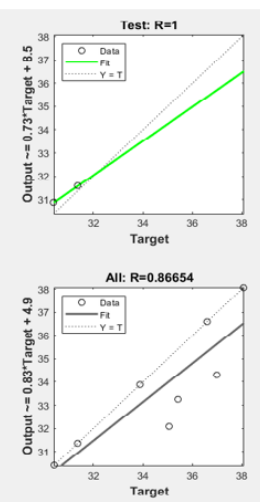

c)

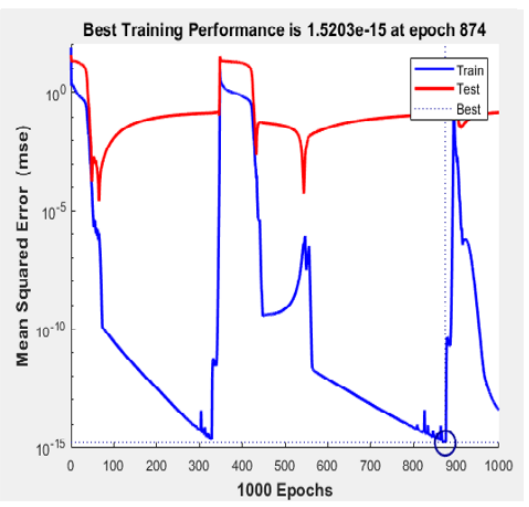

Şekil 2. (a) Porozite Tahmin ve Gerçek Veriler; (b) Regresyon Grafiği; (c) Performans Grafiği.

Şekil 2'in a)'da Porozite tahmin ve gerçek verilerin çok yakın değerler aldığı görülmektedir. (b)'de Regresyon grafiğinde 1'e yaklaştıkça tahmin ve gerçek verilerin benzerliği artmaktadır. (c)'de performans grafiğini göstermektedir.

Hata yüzdelerinin düşük değerleri yapay sinir ağı modellerinin çok yakın tahminlerde bulunduğunu göstermektedir (Balaji N.S. et al, 2016).

a)

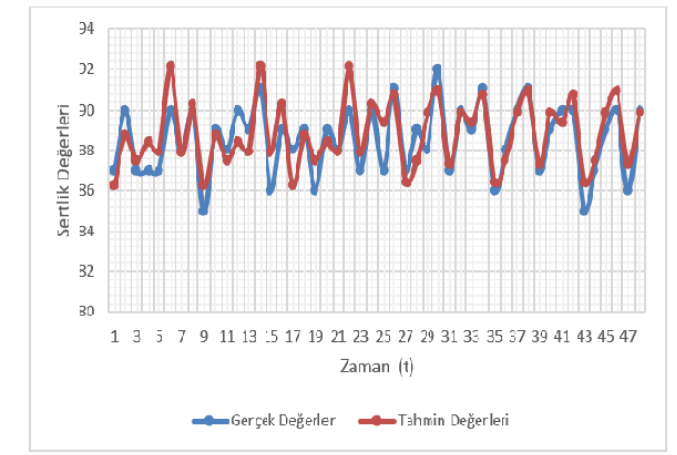

b)

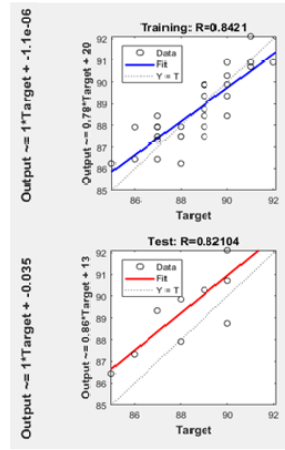

c)

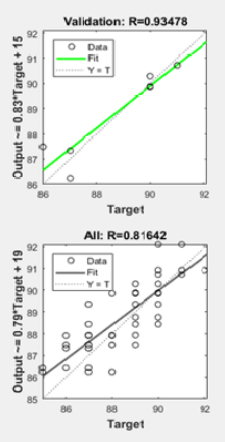

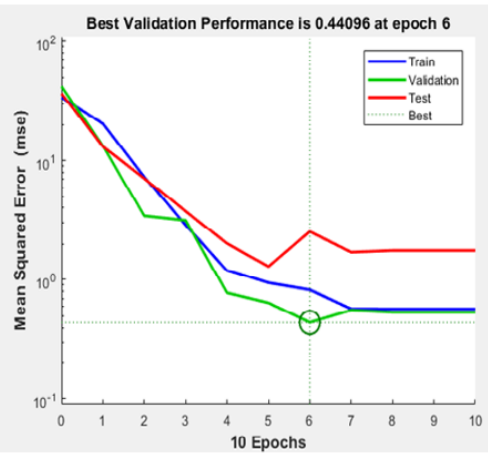

Şekil 3. (a) Shore D Sertlik Testlerinin Tahmin ve Gerçek Veriler; (b) Regresyon Grafiği.; (c) Performans Grafiği.

Şekil 3; (a)'da Shore D Sertlik testi tahmin ve gerçek verilerin çok yakın değerler aldığı görülmektedir. (b)'de Regresyon grafiğinde 1'e yakın değerin burada da tahmin ve gerçek verilerin benzerliğini göstermektedir. (c)'de performans grafiğini göstermektedir.

Yapay sinir ağları en çok kullanılan modellerden biri olması, kapalı bir kutu gibi kullanılıyor olmasıdır (Okkan U.et al, 2018).

a)

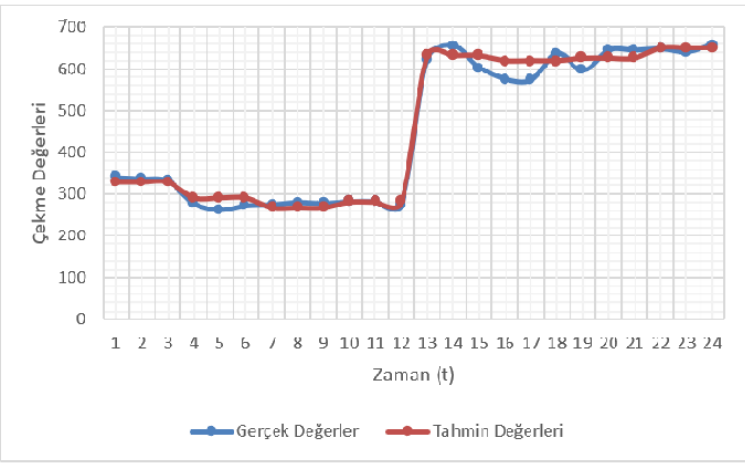

b)
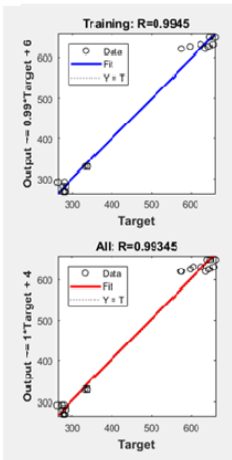

c)

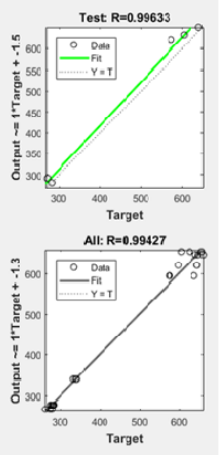

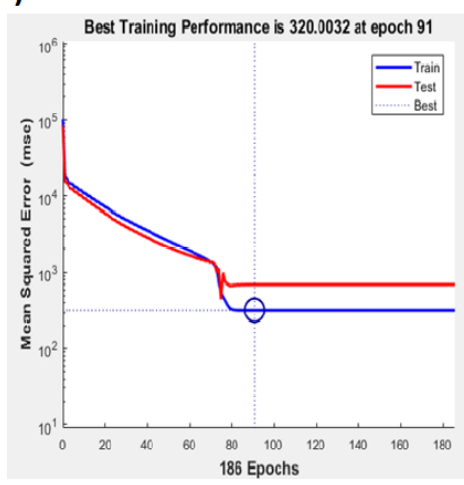

Şekil 4. (a) Çekme Testi Tahmin ve Gerçek Veriler; (b) Regresyon Grafiği.; (c) Performans Grafiği. 
Şekil 4, a)'da Çekme testinde tahmin ve gerçek değerlerin birbirine oldukça yakın olduğu görülmekte olup yüksek derecede benzerlik görülmektedir. (b)'de Regresyon grafiğinde 1'e yaklaştıkça tahmin ve gerçek verilerin benzerliği artmaktadır. Çekme testinde $\mathrm{R}=0,993$ olup çekme testinde sistemin başarısı (MAPE) \%0,14 hata ile çalıştığı görülmektedir. c)'de performans grafiğini göstermektedir.

Modelin minimuma hızla gelmesi sağlanmakla birlikte çok daha güvenilir sonuçlara ulaşmak mümkün olmaktadır (Okkan U. et al, 2018).

a)

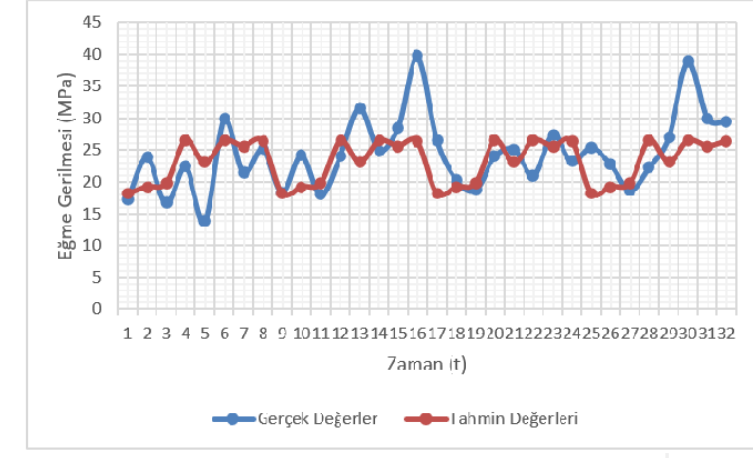

b)
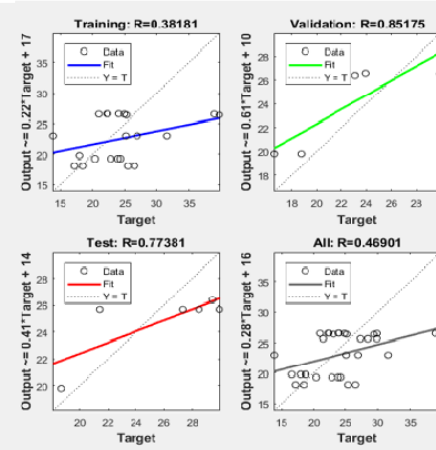

c)

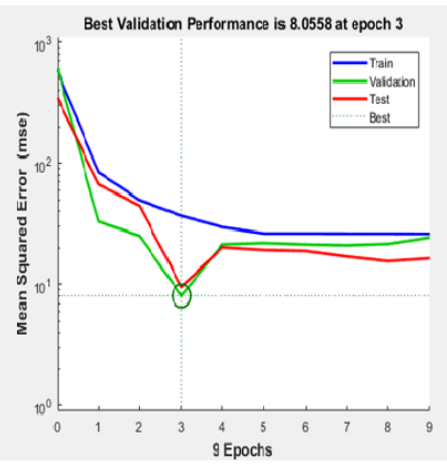

Şekil 5. (a) Eğme Testi Tahmin ve Gerçek Veriler; (b) Regresyon Grafiği.; (c) Performans Grafiği.

Şekil 5; (a)'da Eğme testinde ise \%80 tahmin ve gerçek veriler birbirine yakın değerler aldığı görülmektedir (b)'de Regresyon grafiğinde 1'e yaklaştıkça tahmin ve gerçek verilerin benzerliği artmakta olup eğme testinde $\mathrm{R}=0,773$ olduğu görülmektedir. (c)'de performans grafiğini göstermektedir.

Yapay sinir ağları matlab nftool yöntemiyle eğri uydurmakta oldukça başarılı olmakla birlikte kaç iterasyonda tamamladığını epoch kısmında görülmektedir (Kubat C. vd. 2017).

a)

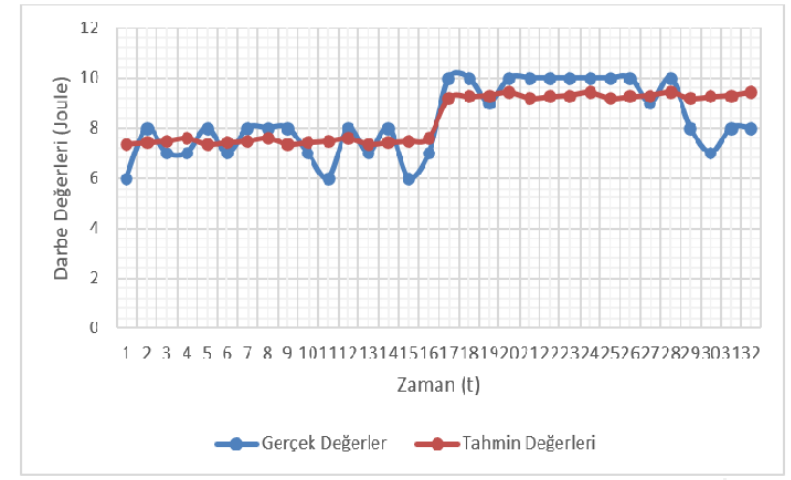

b)
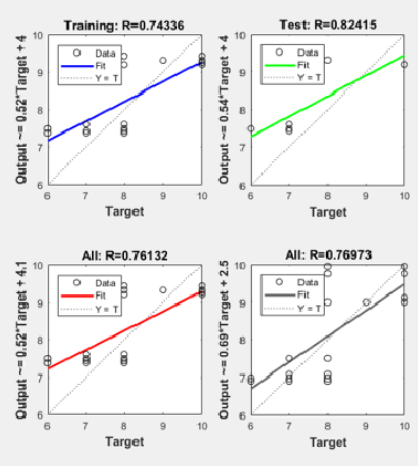

c)

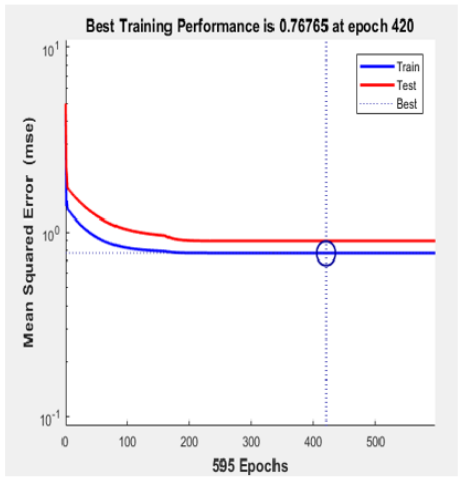

Şekil 6.(a) Darbe Testi Tahmin ve Gerçek Veriler; (b) Regresyon Grafiği.; (c) Performans Grafiği.

Şekil 6; (a)'da Darbe Testi tahmin ve gerçek verilerin yakın değerler aldığı görülmektedir. (b)'de Regresyon grafiğinde Darbe Testi için regresyon değeri $\mathrm{R}=0,761$, (MAPE) \%0,29 hata ile çalıştığı görülmektedir. (c)'de Sistem performansı grafiğini göstermektedir.

Deneysel ve tahmin edilen verilerin \%3, \%4 veya daha az hataya sahip oldukları görülmektedir (Kumar S. et al, 2021). 
a)

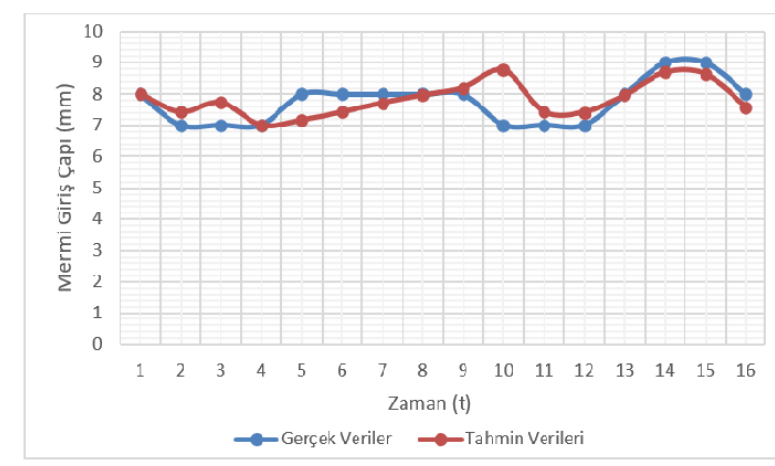

b)
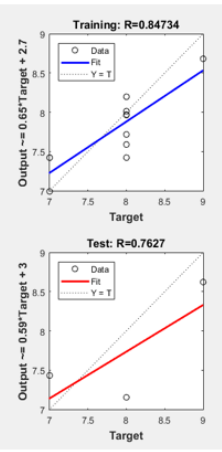

c)

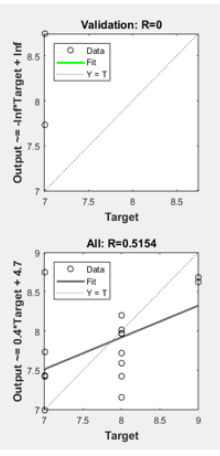

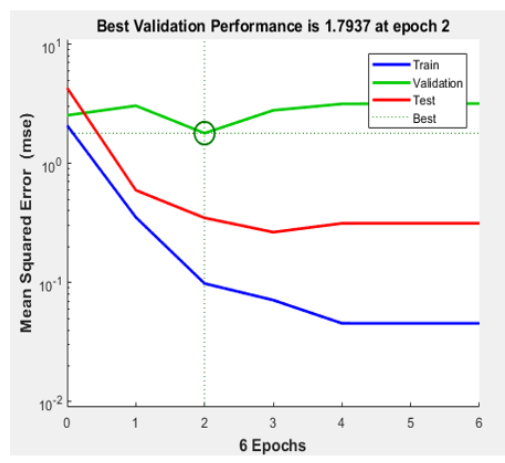

Şekil 7. (a) Balistik Mermi Giriş Çapı Tahmin ve Gerçek Veriler; (b) Regresyon Grafiği.; (c) Performans Grafiği.

Şekil 7; (a)'da Balistik Testi Merminin Giriş Çapının tahmin ve gerçek verilerin yakın değerler aldığı görülmektedir. (b)'de Regresyon grafiğinde Mermi Giriş Çapı ise $\mathrm{R}=0,762$ olduğu (MAPE) \%0,34 hata ile çalışı̆̆ı görülmektedir. (c)'de Sistem performansı grafiğini göstermektedir.

Yapay sinir ağları güçlü bir araç haline gelmesi fonksiyon yaklaşımlarının karmaşık uygulamalara optimizasyon ve doğrusal olmayan sistem tanımlama gibi birçok durumda kolaylık sağlamaktadır (Ramaiah G.B. et al, 2021).

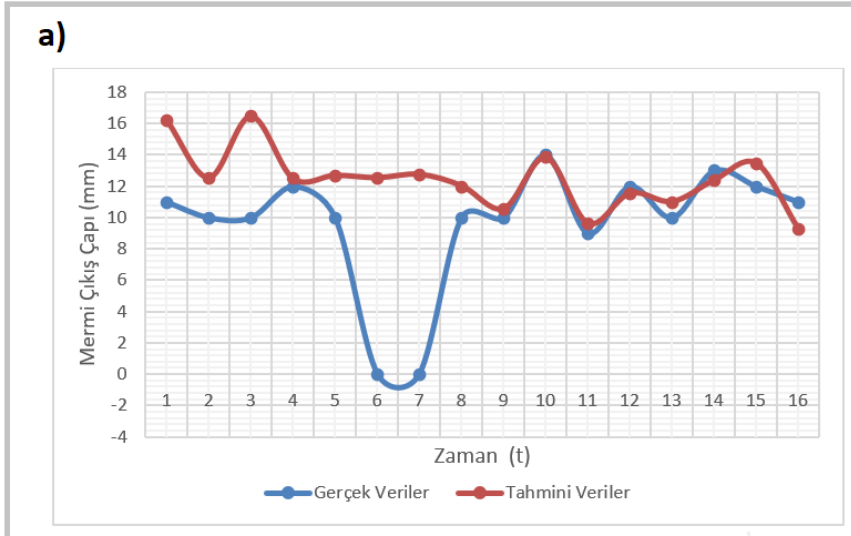

b)
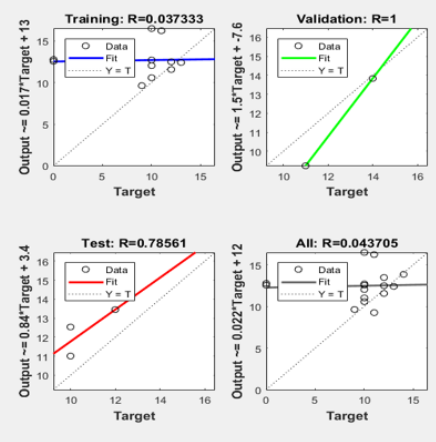

c)

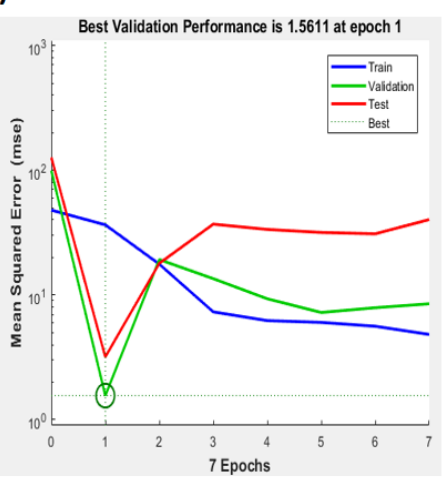

Şekil 8. (a) Balistik Mermi Çıkış Çapı Tahmin ve Gerçek Veriler; (b) Regresyon Grafiği.; (c) Performans Grafiği

Şekil 8; (a)'da Merminin Çıkış Çapının tahmin ve gerçek verilerin yakın değerler aldığı, ancak mermi çıkış çapında bazılarında çapın sıfırın olduğu delinme olmadığı tahmin verilerin de ise bu durumun gerçekleşmemesi veri sayısının artırılması gerektiği anlaşılmaktadır. (b)'de Regresyon grafiğinde Mermi Çıkış Çapı için regresyon değeri $\mathrm{R}=0,785$ olduğu görülmektedir. Sistem başarısı Mermi Çıkış Çapı için (MAPE) \%33,32 hata ile çalışmaktadır. (c)'de performans grafiğini göstermektedir.

Simülasyon teknikleri ve yöntemleriyle balistik test anında yapı davranışlarının genel olarak sonuçların yapay sinir ağlarıyla başarılı olabileceği görülmektedir. Balistik kumaşların malzeme özelliklerinin modellenmesinde kullanılan geleneksel fiber bilimine benzerlik görülmektedir (Ramaiah G.B. et al, 2021). 
a)

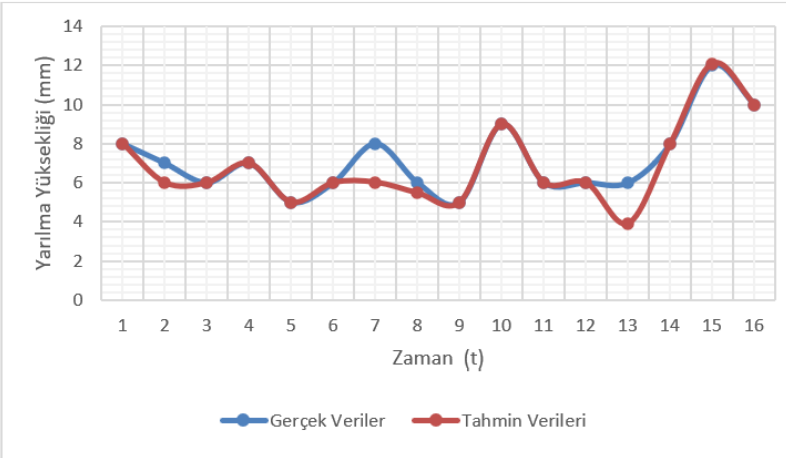

b)
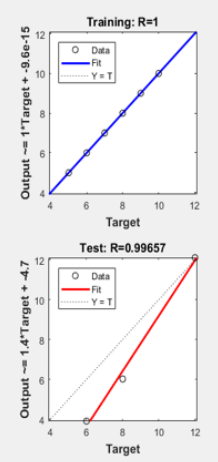
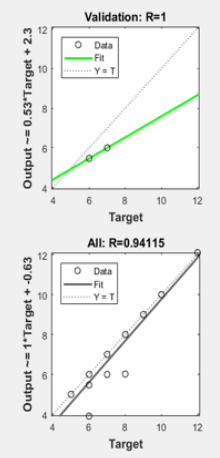

c)

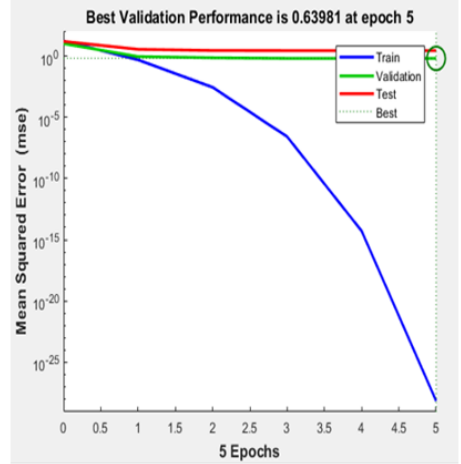

Şekil 9. (a) Balistik Yarılma Yüksekliği Tahmin ve Gerçek Veriler; (b) Regresyon Grafiği.; (c) Performans Grafiğgi.

Şekil 9; (a)'da Numunenin yarılma yüksekliğinin tahmin ve gerçek verilerin yakın değerler aldığı görülmektedir. (b)'de Regresyon grafiğinde Numune Yarılma Yüksekliğinde ise $\mathrm{R}=0,996$ olduğu görülmektedir. Sistem başarısı Numune Yarılma Yüksekliği için $\% 0,30$ Hata ile çalışmaktadır. (c)'de performans grafiğini göstermektedir.

Yapay sinir ağ modeli, kullanılan farklı mimariye göre değişmektedir (Kumar S. et al, 2021).

\section{1. İstatistiksel Bulgular}
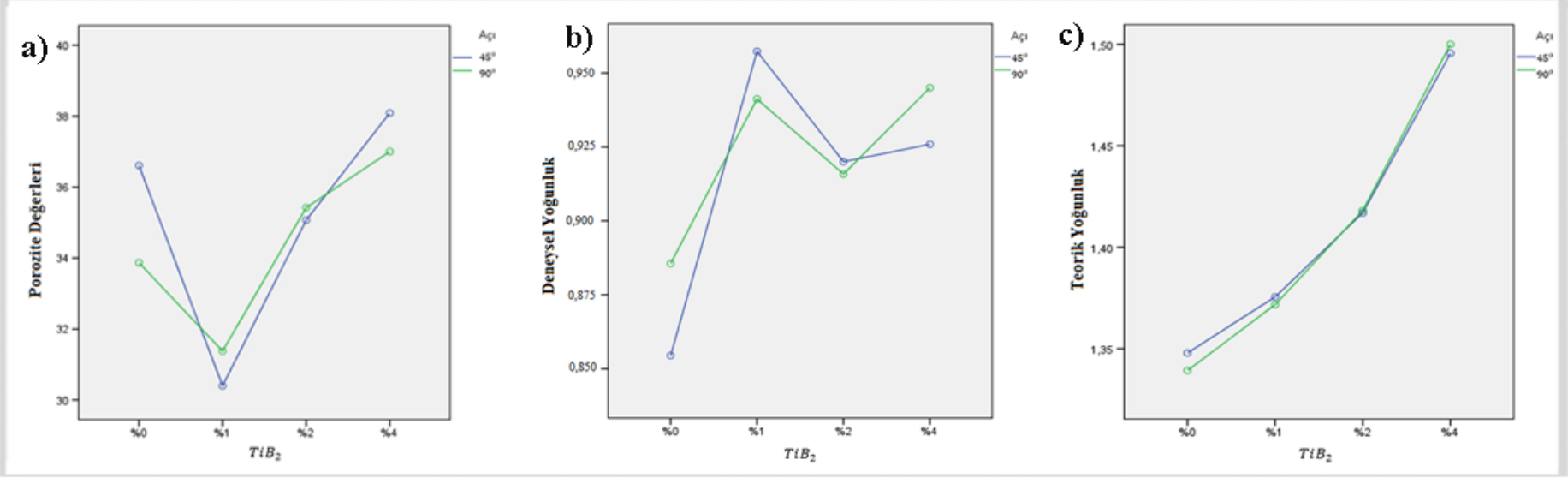

Şekil 10. (a) Porozite (b) Deneysel Yoğunluk Testi (c) Teorik Yoğunluk Testi.

Şekil 10; (1)'in (a)'da hem 45 hem de 90 derecelik oryantasyonda porozitenin en düşük olduğu parametre TiB $2 \% 1$ 'lik olduğu görülmektedir (b)'de Deneysel yoğunluk grafiği incelendiğinde de homojenliğin en iyi sağlandığı parametrenin $\% 1 \mathrm{TiB}_{2}$ olduğu görülmektedir. (c) Teorik yoğunlukta $\mathrm{TiB}_{2}$ oranında değişim oran artıkça teorik yoğunlukta artmaktadır.

Mekanik özelliklerin sonraki işlemlerde önemli değişken ya da parametreyi belirlemek için test edilmektedir (Suresh N. 2021).
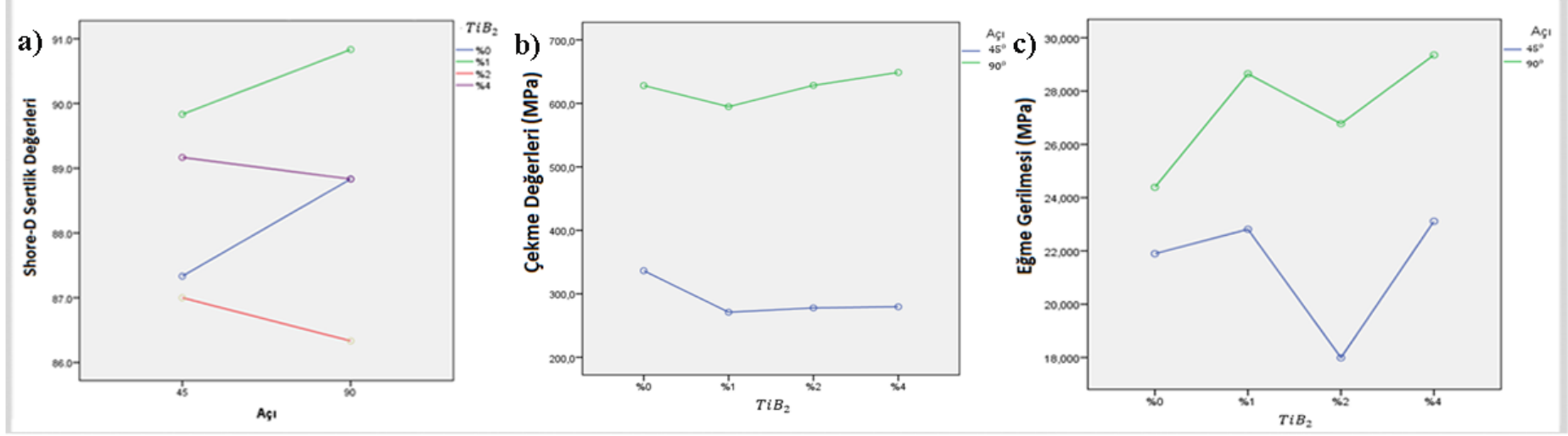

Şekil 11. (a) Shore D Sertlik Testi (b) Çekme Testi (c) Eğme Gerilmeleri. 
Şekil 11; (2)'in 90 derecelik oryantasyonda her birinde değer olarak en üstte olduğundan oryantasyonun anlamlı bir parametre olduğu anlaşılmaktadır. (a) Sertlik testinde en yüksek uç değerlerin \%1'lik $\mathrm{TiB}_{2}$ olduğu görülmekte. (b) Çekme testinde oryantasyonların kendi aralarında durumuna bakıldığın birbirlerine yakın olduğu görülmektedir. (c) Ağırlıkça $\mathbf{T i} \boldsymbol{B}_{\mathbf{2}}$ oranlarına göre eğme gerilmeleri genelde artarken $\% 2$ olan numunelerin daha aşağıda bir değer aldıkları görülmektedir.

Kompozit malzemenin bileşenleri için gerilim gerinim eğrisi analizler için çizilmektedir (Suresh N. 2021; Saraç M.F. vd. 2018).
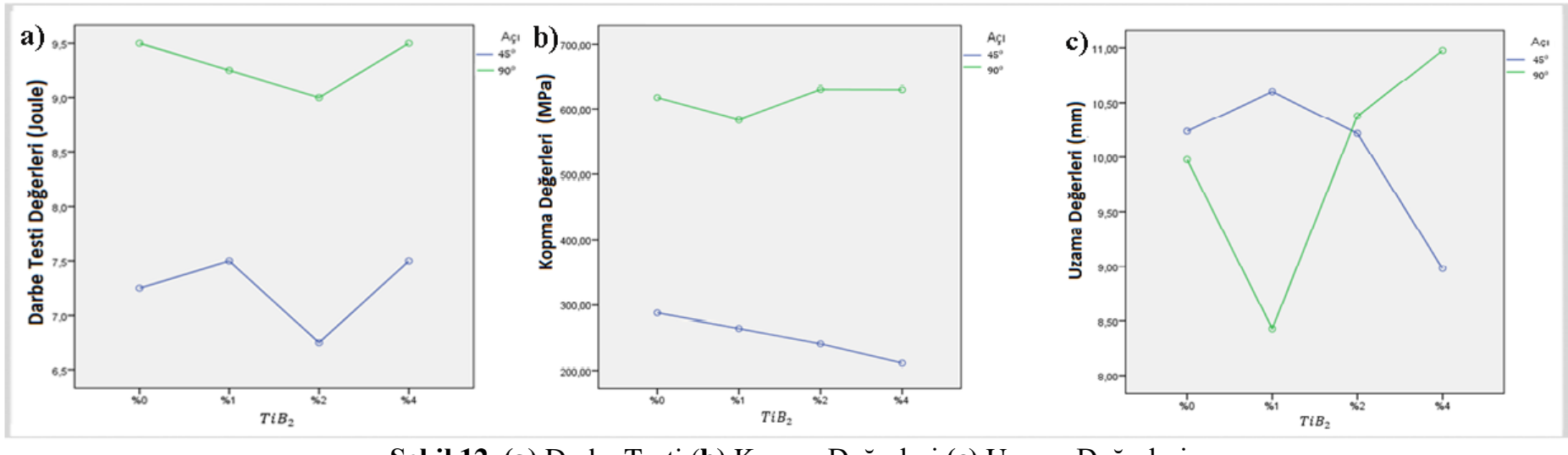

Şekil 12. (a) Darbe Testi (b) Kopma Değerleri (c) Uzama Değerleri

Şekil 12; (3)'in (a) ve (b)'de $90^{\circ}$ oryantasyonun anlamlı bir parametre olduğu görülmektedir. Ağırlıkça TiB 2 oranları arttıkça kopma mukavemetleri azalma olduğu görülmektedir. (c) Ağırlıkça $\mathrm{TiB}_{2}$ oranlarının artıkça $45^{0}$ oryantasyonun uzama miktarlarının azaldığı görülmektedir.

İç içe varyans analizi ile üretimin kalitesini her bir parametreyi tüm kombinasyonlarıyla birlikte yorumlayabilme imkânı vermektedir (Stanimirova L. 2013).
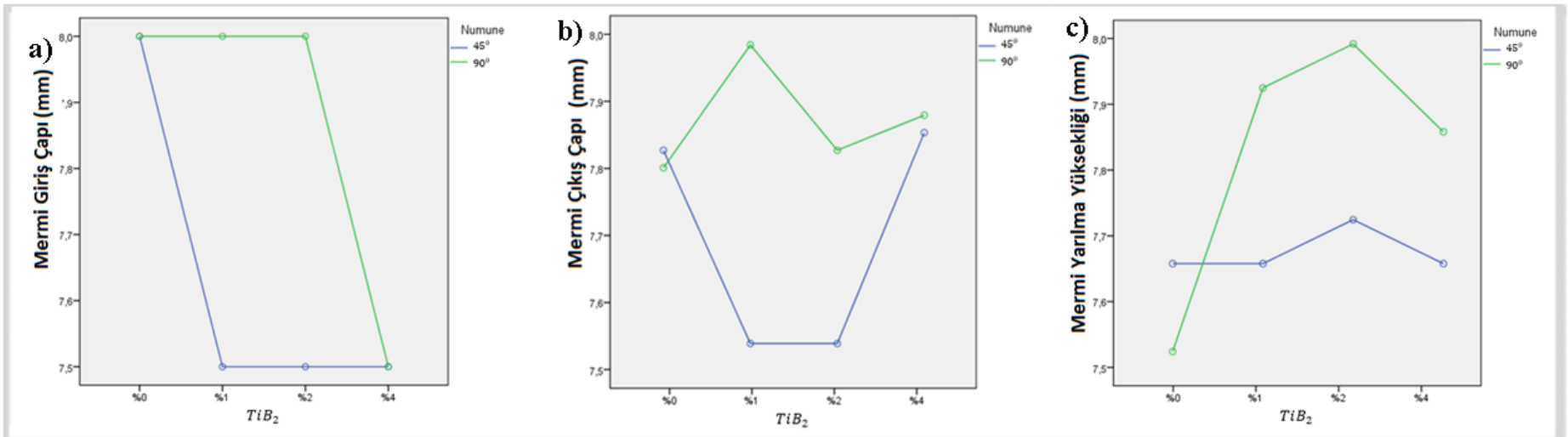

Şekil 13. (a) Merminin Giriş Çapı. (b) Merminin Çıkış Çapı. (c) Numunenin Tahribat Yüksekliği.

Şekil 13; (4)'ün (a)'da $45^{0}$ oryantasyonda ağırlıkça $\mathrm{TiB}_{2}$ oranı artıkça mermi giriş çapı küçülürken, $90^{\circ}$ oryantasyonda ise artışlarda sabit kalırken \%4 olanlarda bir azalma olduğu görülmektedir. (b)'de Mermi çıkış çaplarında $45^{\circ}$ oryantasyon $90^{\circ}$ oryantasyonlara göre daha küçük olduğu görülmektedir. (c) Mermi Yarılma Yüksekliğinin $90^{\circ}$ oryantasyonlarda daha yüksek olması mermi geçirmezliğinin daha iyi olması ya da şarapnel parçacıklarının geçmesini daha iyi tuttuğu anlamına gelebilmektedir.

İstatistiksel analiz, herhangi bir araştırma ve analiz için oldukça değerli ve bilgilendirici bir araçtır. Bu analizde, aşağıdaki sonuçlara yol açan istatistiksel analizler yapılmıştır. Polimer matrisli kompozitlerin üretim süreci, mekanik özelliklere önemli derecede etkin rol almaktadır. Üretim sürecini kontrol etmek ve optimal yöntemi belirlemek için istatistiksel analizlerden yararlanabilmektedir. İstatistiksel analizler, bir araştırmada oldukça önemli, değerli ve bilgilendirici bir araç olduğu görülmektedir (Suresh N. 2021).

\section{Elde Edilen Simülasyon Sonuçları}

Polimer matrisli kompozit olup aramid elyaf takviyeli birçok zırh malzemesi çalışılmış olup mekanik test olarak balistik testler üzerine yapılmaktadır. Bu çalışmada üretilmiş olan zırh plakalarının 8 katlı olup farklı parametrelere sahip olup ve çekme, eğme, darbe, balistik ve sertlik testi gibi birçok mekanik testleri yapılmıştır. Bu mekanik test sonuçlarıyla birlikte elde edilen sonuçların yapay sinir ağlarıyla modellenmesi ve istatistiksel analizlerle analizlerinin yapılmasıyla birlikte üzgünlük kazandırmaktadır. Personel koruma amacıyla 
üretilmiş olan aramid elyaf takviyeli $\mathrm{TiB}_{2}$ ilaveli polimer matris kompozit zırh plakalarının mekanik test sonuçlarından yararlanarak yapay sinir ağlarıyla tahminleri yapılmıştır. İstatistiksel analizlerle ise parametrelerinin tek başına ya da birlikte plakalara etkisinin amaca uygun, anlamlı ya da anlamsız olduğu durumlar incelenmiştir. Analiz sonuçlarına göre en anlamlı ve amaca en uygun $90^{\circ}$ oryantasyona sahip ağırlıkça \%1 $\mathrm{TiB}_{2}$ olan plaka numunelerinde elde edilmiştir. Analiz sonuçları özet olarak aşağıda verilmiştir.

Yapay Sinir Ağlarında; Regresyon grafiği 1'e yaklaştıkça tahmin ve gerçek verilerin benzerliği artmaktadır. Mekanik testlerle elde edilen her bir verinin yapay sinir ağlarıyla modellemesi gerçek değerlerle yakın değer çıktı̆̆ı görülmektedir. Veri sayısı arttırılmasıyla sistemin hata oranını daha da düşürmektedir. Çekme testinde tahmin ve gerçek değerlerin birbirine oldukça yakın olduğu görülmekte olup Eğme testinde ise \%80 tahmin ve gerçek veriler birbirine yakın değerler aldığı görülmektedir. (3) ve (4)'ün (b)'de Regresyon grafiğinde 1'e yaklaştıkça tahmin ve gerçek verilerin benzerliği artmaktadır. Çekme testinde $\mathrm{R}=0,993$ iken Eğme testinde $\mathrm{R}=0,773$ olduğu ve olup çekme testinde sistemin başarısı (MAPE) \%0,14 hata, eğme testinde ise \%0,53 hata ile çalıştığı görülmektedir. Regresyon grafiğinde Darbe Testi için regresyon değeri $\mathrm{R}=0,761$, Mermi Giriş Çapı ise $\mathrm{R}=0,762$ olduğu ve Darbe Testinde (MAPE) $\% 0,29$, Mermi Giriş Çapı ise (MAPE) \%0,34 hata ile çalıştığı görülmektedir. Merminin Çıkış Çapı ile Numunenin yarılma yüksekliğinin tahmin ve gerçek verilerin yakın değerler aldığı, ancak mermi çıkış çapında bazılarında çapın sıfırın olduğu delinme olmadığ 1 tahmin verilerin de ise bu durumun gerçekleşmemesi veri sayısının artııılması gerektiği anlaşılmaktadır. Regresyon grafiğginde Mermi Çıkış Çapı regresyon değeri $\mathrm{R}=0,785$, Numune Yarılma Yüksekliğinde ise $\mathrm{R}=0,996$ olduğu görülmektedir. Sistem başarısı Mermi Çıkış Çapı için (MAPE) \%33,32 hata ile çalışırken Numune Yarılma (Tahribat) Yüksekliği için \%0,30 Hata ile çalışmaktadır.

İstatistiksel analizlerde; $T i B_{2}$ ilavesinde ağırlıkça oran arttıkça yoğunlukları artmakta olup porozite miktarlarında ise azalmalar olduğu görülmüştür. $T i B_{2}$ oranı ağıllıkça $\% 1$ olanlarda gözenek miktarı diğerlerine göre daha az olduğu gözlemlenmiştir. Shore Sertlik testlerinde oryantasyon etkisinin önemsiz olduğu saptanmıştır. Ağırlıkça $\mathrm{TiB}_{2}$ oranlarının sertlik testlerinin anlamlı olduğu gözlenmiştir. Ağırlıkça $T i B_{2}$ oranı ve oryantasyonların birlikte etkileri çekme testi için oldukça olumlu ve anlamlı olduğu görülmüştür. $\mathrm{TiB}_{2}$ tek başına etkisini incelediğimizde çekme testleri için etkisi anlamlı çıkmıştır. Oryantasyona göre incelendiğinde tek başına çekme testleri için olumlu yönde etkisi olmakla birlikte $90^{\circ}$ oryantasyona sahip numuneler $45^{\circ}$ oryantasyona göre çok daha anlamlı olduğu saptanmıştır. Oryantasyonun eğme gerilmelerinde olumlu ve anlamlı bir etkisi olduğu gözlemlenmiştir. Ağırlıkça $T i B_{2}$ oranlarının eğme gerilmelerine istatistiksel olarak anlamlı bir fark olmadığı anlaşılmaktadır. Eğme gerilmeleri oryantasyonla birlikte ağırlıkça $\mathrm{TiB}_{2}$ ilavesi eğme değerlerine istatistiksel olarak etkisinin anlamsız ve istatistiksel olarak anlamlı bir fark olmadığ 1 görülmüştür. Oryantasyonun darbe testine olumlu ve anlamlı bir etkisinin olduğu görülmüştür. $T i B_{2}$ oranlarının darbe testine göre istatistiksel anlamda bir etkisi olmadığı görülmüştür. Açı ve $\mathrm{TiB}_{2}$ darbe testi değerlerine istatistiksel olarak anlamlı bir fark yoktur. Oryantasyonla birlikte ağırlıkça $T i B_{2}$ ilavesi darbe testine etkisinin anlamlı bir fark olmadığı görülmüştür.

\section{Sonuç ve Öneriler}

Literatürde yapılan çalışmalara bakıldığında bu çalışmada da olduğu gibi en çok kullanılan yöntemlerden biri olan yapay sinir ağları kullanılmıştır. Birçok çalışmanın karmaşık yapısını yorumlayabilmek için istatistiksel analizlerinden iç içe veya faktöriyel varyans analizlerinden faydalanılmıştır. Bu çalışmada da her bir mekanik test için $45^{0}-90^{\circ}$ oryantasyona ve ağırlıkça $\mathrm{TiB}_{2}$ oranlarının $\% 0,1,2$ ve 4 değerlerinin etkisi ölçülmüş ve yorumlanmıştır. Sonuç olarak yapay sinir ağları analizi ile istatistiksel analizler parametreleri ağırlıkça $\mathrm{TiB}_{2}$ oranı $\% 1$ ve $90^{\circ}$ oryantasyona sahip olan numuneler diğerlerine göre daha baskın oldukları görülmektedir. Öneriler; Yapılan çalışmaya baktığımızda yapay sinir ağlarına yönelik her bir mekanik test için veri sayısı için daha fazla test sonuçlarından faydalanabilir. İstatistiksel analizlerle belirlenmiş olan optimal üretimi ele alınarak yeni parametreler dahil edilmesi daha da geliştirilebilir. Hem geliştirmek hem de maliyet yönü baz alındığında takviye malzemesi olan elyafları birleştirerek hibrit kompozit malzemeler üzerine bir çalışmanın farklı kat ve türevlerinin analizleriyle birlikte kıyaslamalar yapılabilir.

\section{Referanslar}

Akşehirli Ö., Cangür Ş, Ankaralı H., Sungur M.A. (2012). $2^{4}$ Faktöriyel Tasarımların Sağlık Alanında Kullanımı. Düzce Üniversitesi Sağlı Bilimleri Enstitüsü Dergisi, 2(3): 1-6.

Balaji R., Nadarajan M., Selokar A., Kumar S.S., Sivakumar S. (2019). Modelling And Analysis of Disk Brake Under Tribological Behaviour of Al-Al2O3 Ceramic Matrix Composites/Kevlar ${ }^{\circledR} 119$ Composite/C/Sic-Carbon Matrix Composite/Cr-Ni-Mo-V Steel. Proceedings 18, 3415-3427.

Balaji N. S., Jayabal S., Kalyana S. (2016). A. Neural Network Based Prediction Modeling for Machinability Characteristics of Zea Fiber-Polyester Composites. Trans Indian Inst Met (2016) 69(4):881-889.

Chen CT ve Gu GX (2019). Machine Learning For Composite Materials. MRS Communications Volume 9, Issue 2, 556-566.

Eyecioğlu Ö. (2021). Bazalt/PANI Kompozitlerinin Dielektrik Özelliklerinin Tahmini İçin Makine Öğrenmesi Modellerinin Karşılaştırılması. Avrupa Bilim ve Teknoloji Dergisi, Sayı 23, S. 817-826. 
Fazilat H., Ghatarband M., Mazinani S., Asadi Z.A, Shiri M.E., Kalaee M.R. (2012). Predicting The Mechanical Properties Of Glass Fiber Reinforced Polymers Via Artificial Neural Network And Adaptive Neuro-Fuzzy İnference System. Computational Materials Science 58 (2012) 31-37.

Gedik İ. (2010). İç-içe Tasarımlarda Dayanıklı Analiz ve Uygulamaları. Yüksek Lisans Tezi Ankara Üniversitesi Fen Bilimleri Enstitüsü İstatistik Anabilim Dalı, Ankara, 93 Sayfa.

James R. Brown, Daryl K.C. Hodgeman (1982). An E.s.r. Study of the Thermal Degradation of Kevlar 49 Aramid., Volume 23, Issue 3, March 1982, Pages 365-368.

Kubat C., Kiraz A., Atakan Ü. (2017). Matlab Yapay Zekâ ve Mühendislik Uygulamaları Kitabı, İstanbul, Abaküs Yayınları.

Kumar S.S., Priyadarshan, Kumar G. S. (2021). Statistical and Artificial Neural Network Technique for Prediction of Performance İn AlSi10Mg-MWCNT Based Composite Materials. Department of Mechanical Engineering, Indian Institute of Technology (ISM) Dhanbad, 826004, Volume 273, 125136.

Kadi H.E. (2006). Modeling the mechanical behavior of fiber-reinforced polymeric composite materials using artificial neural networks-A review. Composite Structures Volume 73, Issue 1, May 2006, Pages 1-23.

Kuwada M. (1993). Analysis of Variance of Balanced Fractional Factorial Designs. Discrete Mathematics Volume 116, Issues 1-3, 1 June 1993, Pages 335-366.

Madara S.R., Pillai S.R., Selvan M. C.P., Heirle J.V. (2021). Modelling of Surface Roughness in Abrasive Waterjet Cutting of Kevlar 49 Composite Using Artificial Neural Network. 2214-7853/ Elsevier, Volume 46, Part 1, 2021, Pages 1-8.

Mays D.P. and Myers R.H. (1997). Design and Analysis for a Two-Level Factorial Experiment in The Presence of Variance Heterogeneity. Computational Statistics \& Data Analysis Volume 26, Issue 2, 4 December 1997, Pages 219-233.

Morrison D.A. (2002). Further Difficulties With Multifactorial Analysis of Variance: Random and Nested Factors and İndependence of Data. Infection, Genetics and Evolution Volume 2, Issue 2, December 2002, Pages 149-152.

Nguyen H.T., Nguyen K.T.Q, Tu C. Le, Soufeiani L., Mouritz A.P (2021). Predicting Heat Release Properties of Flammable FiberPolymer Laminates Using Artificial Neural Networks. Composites Science and Technology 215, 109007.

Okkan U., Serbeş Z.A., Gedik N. (2018). MATLAB ile Levenberg-Marquardt Algoritması Tabanlı YSA Uygulaması. DÜMF Mühendislik Dergisi 9:1 (2018): 351-362.

Ramaiah G.B., Chennaiah R.Y., Satyanarayanarao G.K. (2021). Investigation And Modeling On Protective Textiles Using Artificial Neural Networks For Defense Applications. Materials Science And Engineering B 168 (2010) 100-105.

Saraç M.F, Buran D., Koru M. (2018). Investigation of Thermal and Mechanical Properties of Aramid Fiber Reinforced Thermoplastic Polyurethane Elastomer Composites. Süleyman Demirel University Journal of Natural and Applied Sciences V.22, Issue 2, 477-481.

Stanimirova L., Kazura M., Beer D.D., Joubert E., Schulzec A.E., Beeldersc T., Villiers A.D., Walczak B. (2013). High-Dimensional Nested Analysis of Variance to Assess the Effect of Production Season, Quality Grade and Steam Pasteurization on The Phenolic Composition of Fermented Rooibos Herbal Tea. Talanta, Volume 115, 15 October 2013, Pages 590-599.

Suresh N., Balamurugan L., Geethan K.A.V., Kumar M.S. (2021). Statistical Analysis of Mechanical Properties of Al-SiC-WC and $\mathrm{Al}-\mathrm{SiC}-\mathrm{Al}_{2} \mathrm{O}_{3}$ Hybrid Composites. Materials Today: Proceedings, Volume 42, Part 2, 2021, Pages 312-318.

Wanga F., Huanga G., Cheng G., Li Y. (2021). Multi-Level Factorial Analysis for Ensemble Data-Driven Hydrological Prediction. Advances in Water Resources Volume 153, July 2021, 103948.

Zhang Z., Friedrich K. (2003). Artificial Neural Networks Applied to Polymer Composites. Composites Science and Technology 63, 2029-2044. 